Indo. J. Chem. Res., 2019, 7(1), 25-31

\title{
UJI AKTIVITAS ANTIOKSIDAN EKSTRAK METANOL BIJI KESUMBA KELING (Bixa orellana $\mathrm{L}$ )
}

\author{
Antioxidant Activity Test Of Methanol Extract Of Kesumba Keling \\ (Bixa orellana $\mathbf{L}$ ) Seeds
}

\author{
Fensia Analda Souhoka*, Nikmans Hattu, Marsye Huliselan \\ Department of Chemistry, Faculty Mathematics and Natural Science, Pattimura University, \\ Jl. Ir. Putuhena No. 1 Poka Ambon 97233-Maluku \\ *Corresponding author, e-mail: fensia@fmipa.unpatti.ac.id
}

Received: Jan. 2019 Published: Jul. 2019

\begin{abstract}
Kesumba keling (Bixa orellana $L$ ) has been widely used as a natural dye on lips, hair, and cloth. The red pigment in kesumba keling seeds comes from a bixin and norbixin compound which have many conjugated double bonds, so it has the potential of antioxidants. This study aims to determine the antioxidant compound and an antioxidant activity of methanol extract of kesumba keling seeds. The moisture content of kesumba keling seeds is $78.74 \%$. The powder of kesumba keling seeds was extracted using maceration method with $80 \%$ of methanol. Phytochemical test results of methanol extract positively contained flavonoid compound. An antioxidant activity test of methanol extract of kesumba keling seeds was carried out by determining DPPH free radical deterrent activity. The absorbance measurement were made using a UV-Vis spectrophotometer at a wavelength of $517 \mathrm{~nm}$. Kesumba keling seeds extract has antioxidant activity which is indicated by $\mathrm{IC}_{50}$ value of $69.425 \mathrm{ppm}$, so it is classified as a strong antioxidant.
\end{abstract}

Keywords: Antioxidant activity, kesumba keling seeds, methanol extract, phytochemical test.

\section{PENDAHULUAN}

Makanan dan minuman olahan umumnya dibuat dengan menambahkan pewarna sintetik agar lebih menarik bagi konsumen. Pewarna sintetis menyebabkan dampak yang tidak baik dalam jangka panjang, salah satunya dapat menyebabkan kanker. Oleh karena itu, pemanfaatan bahan alam sebagai sumber pewarna alami pada bahan pangan perlu dimaksimalkan.

Kesumba keling merupakan salah satu tanaman perdu yang ditanam di pekarangan rumah atau di pinggiran jalan sebagai tanaman hias dan pelindung. Bijinya berbentuk bulat telur dan mempunyai selaput berwarna merah. Biji kesumba mengandung senyawa biksin dan norbiksin, yaitu golongan karotenoid tetraterpenoid, yang merupakan pigmen larut air dan lipid, serta tersebar luas hampir ke semua jenis tumbuhan. Biksin $\left(\mathrm{C}_{25} \mathrm{H}_{30} \mathrm{O}_{4}\right)$ adalah suatu asam karboksilat karotenoid dan merupakan pewarna organik yang tidak berbahaya (Gardjito, 2013).

Senyawa biksin dan norbiksin memiliki struktur yang terdiri dari banyak ikatan rangkap terkonjugasi, sehingga berpotensi sebagai antioksidan, antijamur, antikanker, antiinflamatori, antimutagenik, dan antigenotoksik (Suparmi dan Martosupono, 2008, Rustiah, dkk., 2018, Mahardika dkk., 2018). Antioksidan merupakan senyawa yang dapat menghambat reaksi oksidasi dengan cara mengikat radikal bebas dan molekul yang sangat reaktif. Serangan radikal bebas terhadap molekul di sekelilingnya akan menyebabkan terjadinya reaksi berantai, yang kemudian menghasilkan senyawa radikal baru. Dampak reaktivitas senyawa radikal bebas menyebabkan kerusakan sel atau jaringan, penyakit autoimun, penyakit degeneratif, hingga kanker (Sadikin, 2001).

Potensi biji kesumba keling sebagai pewarna sekaligus antioksidan alami perlu untuk dikembangkan, sehingga dapat menggantikan pewarna sintetis. Mira dkk.(2013), menggunakan etanol untuk mengekstrak biji kesumba keling sebagai pewarna bibir. Pujilestari (2014), mengekstrak zat warna biji kesumba keling dengan air untuk digunakan sebagai pewarna pada kain batik katun. Menurut Purwaningsih 
(2013), biji kesumba keling dapat digunakan sebagai pewarna makanan dan antioksidan.

Pada penelitian ini dilakukan uji aktivitas antioksidan ekstrak metanol biji kesumba keling melalui penentuan aktivitas penangkal radikal bebas DPPH menggunakan spektrofotometer UV-Vis. Parameter hasil pengujian dengan metode DPPH adalah $\mathrm{IC}_{50}$ (inhibition concetration), yaitu konsentrasi larutan sampel yang menyebabkan reduksi terhadap aktivitas DPPH sebesar 50\%. Menurut Molyneux (2004), secara spesifik suatu senyawa dikatakan sebagai antioksidan sangat kuat jika nilai $\mathrm{IC}_{50}<50 \mathrm{ppm}$, kuat $50<\mathrm{IC}_{50}<100 \mathrm{ppm}$, sedang $100<\mathrm{IC}_{50}<150 \mathrm{ppm}$, lemah 150 ppm $<\mathrm{IC}_{50}<200$ ppm, dan sangat lemah $\mathrm{IC}_{50}>200 \mathrm{ppm}$.

Penelitian meliputi penentuan kadar air biji kesumba keling, ekstraksi biji kesumba keling dengan metode maserasi menggunakan metanol $80 \%$, kemudian dilakukan uji fitokimia terhadap ekstrak, yaitu uji fenolik, uji flavonoid, uji tanin, penentuan kandungan total fenolik, dan penentuan kandungan total flavonoid. Ekstrak metanol biji kesumba diharapkan dapat diaplikasikan secara maksimal sebagai antioksidan alami dalam industri pangan, kosmetik, dan farmasi.

\section{METODOLOGI}

Alat

Alat-alat yang digunakan yaitu peralatan gelas laboratorium (pyrex), hot plate (Cimarec 2), rotary evaporator (Rotavapor R-215 Buchii), neraca analitik (Electronic Balance), mikropipet, dan vortex. Instrumentasi kimia yang digunakan adalah spektrofotometer UV-Vis (Apel PD-3000 UV).

\section{Bahan}

Bahan dasar yang digunakan adalah biji kesumba keling. Bahan-bahan lain yang digunakan dengan kualitas pro analisis dari Merck, yaitu metanol, reagen Folin-Ciocalteu, natrium karbonat $2 \%, \mathrm{FeCl}_{3} 1 \%$, serbuk $\mathrm{Mg}, \mathrm{HCl}$ $1 \%, \mathrm{AlCl}_{3} 2 \%, \mathrm{DPPH}$, kuersetin (Sigma), kertas saring, dan akuades.

\section{Prosedur Kerja \\ Preparasi Sampel}

Biji kesumba keling segar dikeringkan di dalam oven pada suhu $50^{\circ} \mathrm{C}$ sampai berat konstan, kemudian dihitung kadar air. Sampel kering diblender, kemudian disaring menggunakan ayakan 100 mesh hingga menjadi serbuk.

\section{Ekstraksi biji kesumba keling}

Serbuk biji kesumba keling sebanyak $10 \mathrm{~g}$ dimasukkan ke dalam Erlenmeyer dan ditambahkan $200 \mathrm{~mL}$ metanol $80 \%$ hingga sampel terendam, selanjutnya dimaserasi selama 12 jam. Hasil ekstraksi disaring, kemudian filtrat diuapkan menggunakan rotavapor. Ekstrak metanol biji kesumba keling yang diperoleh ditimbang, kemudian dilakukan uji fitokimia.

\section{Uji Fitokimia}

Uji fenolik (Harbone, 2006)

Ekstrak metanol sebanyak $2 \mathrm{~mL}$ dimasukkan ke dalam tabung reaksi dan ditambahkan 2 tetes $\mathrm{FeCl}_{3} 1 \%$ kemudian dikocok. Uji positif apabila menghasilkan warna biru pekat.

Uji flavonoid (Nafisah dkk., 2014)

Ekstrak metanol sebanyak $2 \mathrm{~mL}$ dimasukkan ke dalam tabung reaksi dan ditambahkan sedikit serbuk $\mathrm{Mg}$ dan $1 \mathrm{~mL} \mathrm{HCl}$ $1 \%$. Uji positif bila menimbulkan busa dan berwarna jingga.

Uji tanin (Tiwari dkk., 2011)

Ekstrak metanol sebanyak $2 \mathrm{~mL}$ dimasukkan ke dalam tabung reaksi dan ditambahkan dengan $1 \mathrm{~mL}$ akuades kemudian dididihkan. Selanjutnya disaring dan filtratnya ditambahkan 2-3 tetes $\mathrm{FeCl}_{3} 1 \%$ dan dikocok. Uji positif bila menghasilkan warna hijau pekat atau biru pekat.

Penentuan kandungan total fenolik (Conde dkk., 1997)

Kandungan total fenolik ditentukan menggunakan metode Folin-Ciocalteau. Fenol dengan konsentrasi $0,1,2,3,4$, dan 5 ppm dibuat sebagai kurva standar, kemudian analisis dengan dua kali pengukuran. Sebanyak $0,1 \mathrm{~mL}$ ekstrak metanol biji kesumba keling dimasukkan ke dalam tabung reaksi dan ditambahkan $0,1 \mathrm{~mL}$ reagen Folin-Ciocalteu 50\%. Campuran dihomogenkan menggunakan vortex, kemudian ditambahkan $2 \mathrm{~mL}$ larutan natrium karbonat $2 \%$. Selanjutnya larutan disimpan dalam ruang gelap 
selama 30 menit. Absorbansi diamati pada panjang gelombang $750 \mathrm{~nm}$. Kandungan total fenolik dinyatakan sebagai ekuivalen fenol dalam mg/g ekstrak.

Kandungan total fenolik $=\frac{\mathrm{M} \times \mathrm{V}}{\mathrm{W}} \times \mathrm{FP}$

Keterangan:

$\mathrm{M}=$ Konsentrasi fenolik (ppm)

$\mathrm{V}=$ Volume sampel $(\mathrm{L})$

$\mathrm{W}=$ Berat sampel $(\mathrm{g})$

$\mathrm{FP}=$ Faktor pengenceran

\section{Penentuan kandungan total flavonoid} (Alhabsyi, dkk. 2014)

Kuersetin dengan konsentrasi 2, 4, 6, 8, dan 10 ppm dibuat sebagai kurva standar, selanjutnya dianalisis dengan dua kali pengukuran. Sebanyak 0,1 mL ekstrak metanol kesumba keling dimasukkan ke dalam tabung reaksi dan ditambahkan $2 \mathrm{~mL} \mathrm{AlCl}_{3} 2 \%$. Campuran diaduk kemudian absorbansinya diamati pada panjang gelombang $415 \mathrm{~nm}$. Kandungan total flavonoid dinyatakan sebagai ekuivalen kuersetin dalam $\mathrm{mg} / \mathrm{g}$ ekstrak.

Kandungan total flavanoid $=\frac{\mathrm{E} \times \mathrm{V} \times \mathrm{FP} \times 10^{-6}}{\mathrm{~W}}$

Keterangan:

$\mathrm{E}=$ Ekivalen kuersetin (ppm)

$\mathrm{V}=$ Volume sampel $(\mathrm{L})$

$\mathrm{W}=$ Berat sampel $(\mathrm{g})$

$\mathrm{FP}=$ Faktor pengenceran

\section{Pembuatan larutan DPPH 40 ppm}

Sebanyak 0,01 g DPPH dimasukkan ke dalam labu takar $250 \mathrm{~mL}$ kemudian ditambahkan metanol hingga tanda batas. Larutan segera digunakan dan dijaga pada temperatur rendah dan terlindung dari cahaya.

\section{Penentuan panjang gelombang maksimum DPPH}

Sebanyak $5 \mathrm{~mL}$ larutan DPPH $40 \mathrm{ppm}$ diamati serapannya pada panjang gelombang 490-534 nm dengan menggunakan blanko metanol.

\section{Penentuan aktivitas penangkal radikal bebas DPPH (Mulyani dkk., 2013)}

Sebanyak $2 \mathrm{mg}$ ekstrak metanol biji kesumba keling dibuat menjadi larutan dengan konsentrasi 10, 20, 30, 40, 50, dan 100 ppm. Larutan pembanding kuersetin dibuat dengan konsentrasi 2,5; 5,0; 7,5; 10; dan 20 ppm. Masing-masing larutan uji sebanyak $1 \mathrm{~mL}$ dimasukkan ke dalam tabung reaksi dan ditambahkan $2 \mathrm{~mL}$ larutan DPPH $40 \mathrm{ppm}$, kemudian didiamkan selama 30 menit pada suhu kamar. Pengukuran absorbansi dilakukan pada panjang gelombang $517 \mathrm{~nm}$ menggunakan spektrofotometer UV-Vis. Pengujian dilakukan dengan dua kali pengukuran. Selanjutnya dihitung nilai $\mathrm{IC}_{50}$ berdasarkan persamaan regresi yang diperoleh. $\mathrm{IC}_{50}$ merupakan konsentrasi ekstrak yang menghambat aktivitas DPPH sebesar $50 \%$. Semakin kecil nilai $\mathrm{IC}_{50}$, semakin tinggi aktivitas antioksidan.

\section{HASIL DAN PEMBAHASAN}

\section{Preparasi Sampel}

Biji buah kesumba keling dikeringkan dalam oven sampai berat konstan, diperoleh kadar air 78,74\%. Sampel kering dihaluskan hingga menjadi serbuk berukuran 100 mesh.

\section{Ekstraksi Sampel}

Serbuk biji buah kesumba diekstrak dengan metanol $80 \%$ menggunakan metode maserasi selama 12 jam. Diperoleh ekstrak berwarna merah bata, selanjutnya ekstrak disaring, kemudian filtrat diuapkan menggunakan rotavapor.

\section{Uji Fitokimia \\ Uji fenolik}

Uji fenolik akan menunjukkan hasil positif dengan terbentuknya warna biru pekat bila ekstrak direaksikan dengan $\mathrm{FeCl} 1 \%$, sesuai reaksi pada Gambar 1. Uji menunjukkan hasil negatif, ditandai dengan perubahan warna sampel dari merah bata menjadi coklat tua.

\section{Uji flavonoid}

Untuk mengetahui ada tidaknya senyawa flavonoid dalam ekstrak dilakukan analisis dengan uji Shinode menggunakan $\mathrm{HCl} 1 \%$ dan serbuk Mg, seperti reaksi pada Gambar 2. Uji menunjukkan hasil positif, ditandai dengan perubahan warna sampel dari merah bata menjadi jingga. Reaksi uji flavonoid menurut Nafisah dkk. (2014) adalah sebagai berikut. 
Fensia A. Souhoka dkk. / Indo. J. Chem. Res., 2019, 7(1), 25-31

$$
\begin{aligned}
& \mathrm{Mg}_{(\mathrm{s})}+2 \mathrm{HCl}_{(\mathrm{l})} \rightarrow \mathrm{MgCl}_{2(\mathrm{aq})}+ \mathrm{H}_{2(\mathrm{~g})} \\
& \mathrm{MgCl}_{2 \text { (aq) }}+6 \mathrm{ArOH}_{(\mathrm{s})} \rightarrow \underset{\left(\mathrm{Mg}(\mathrm{OAr})_{6}\right]^{-4}{ }_{(\mathrm{aq})}+}{ }+\mathrm{H}_{(\mathrm{aq})}^{+}+2 \mathrm{Cl}_{(\mathrm{aq})}
\end{aligned}
$$

\section{Uji tanin}

Uji positif adanya senyawa tanin ditandai dengan terbentuknya endapan putih bila ekstrak direaksikan dengan $\mathrm{FeCl}_{3} 1 \%$. Uji menunjukkan hasil negatif, ditandai dengan perubahan warna sampel dari merah bata menjadi coklat muda.

\section{Penentuan kandungan total fenolik}

Senyawa fenol diketahui memiliki aktivitas antioksidan. Pengujian dan penentuan kandungan total fenolik merupakan dasar dilakukan pengujian aktivitas antioksidan.

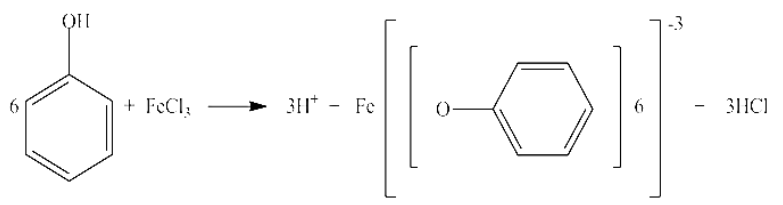

Gambar 1. Reaksi uji fenolik (Harbone, 2006)

Penentuan kandungan total fenolik diukur menggunakan metode Folin-Ciocalteu dan diamati serapan pada panjang gelombang 750 $\mathrm{nm}$. Dari hasil pengukuran diperoleh absorbansi larutan standar fenol seperti disajikan pada Tabel 1.

Tabel 1. Hasil pengukuran absorbansi larutan

\begin{tabular}{ccc}
\multicolumn{3}{c}{ standar fenol } \\
\hline No & $\begin{array}{c}\text { Konsentrasi fenol } \\
(\mathrm{ppm})\end{array}$ & Absorbansi \\
\hline 1 & 0,00 & 0,000 \\
2 & 1,00 & 0,276 \\
3 & 2,00 & 0,315 \\
4 & 3,00 & 0,553 \\
5 & 4,00 & 0,792 \\
6 & 5,00 & 0,824 \\
\hline
\end{tabular}

Dari hasil yang diperoleh, dibuat kurva standar fenol seperti ditunjukkan pada Gambar 2.

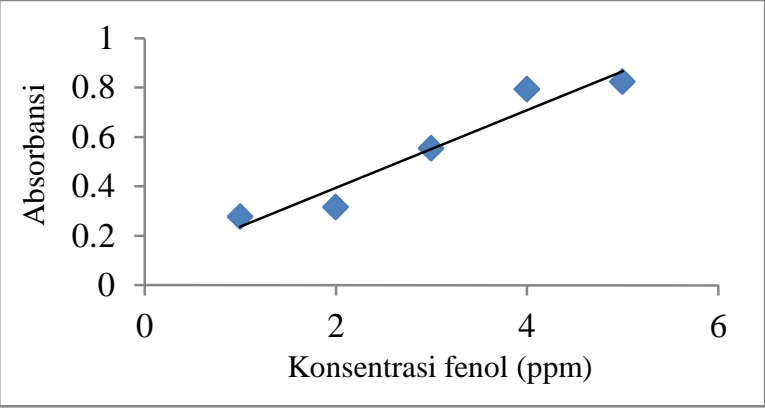

Gambar 2. Kurva standar fenol

Nilai absorbansi yang diperoleh dari tiap ekstrak diplotkan terhadap kurva standar fenol dan dihitung kandungan total fenoliknya. Kandungan total fenolik ekstrak metanol biji kesumba keling adalah 0,00595 mg/g ekstrak. Pada penentuan kandungan total fenolik terjadi perubahan warna dari kuning menjadi hijau, yang merupakan hasil dari reaksi antara senyawa fenolik dalam ekstrak dengan reagen FolinCiocalteu yang ditunjukkan pada Gambar 3.

\section{Penentuan Kandungan Total Senyawa Flavonoid}

Penentuan kandungan total senyawa flavonoid dilakukan dengan mengamati serapan pada panjang gelombang $415 \mathrm{~nm}$. Absorbansi standar kuersetin disajikan pada Tabel 2.

Tabel 2. Hasil pengukuran absorbansi larutan standar kuersetin

\begin{tabular}{ccc}
\hline No & $\begin{array}{c}\text { Konsentrasi } \\
\text { kuersetin }(\mathrm{ppm})\end{array}$ & Absorbansi \\
\hline 1 & 2 & 0,125 \\
2 & 4 & 0,224 \\
3 & 6 & 0,361 \\
4 & 8 & 0,473 \\
5 & 10 & 0,583 \\
\hline
\end{tabular}

Dari hasil pengukuran, dibuat kurva standar kuersetin seperti ditunjukkan pada Gambar 4. Berdasarkan nilai absorbansi yang diperoleh dari tiap ekstrak diplotkan terhadap kurva standar kuersetin (Gambar 4) dan dihitung kandungan total flavonoid. Kandungan total flavonoid ekstrak metanol biji kesumba keling adalah $0,6689 \mathrm{mg} / \mathrm{g}$ ekstrak. 
Fensia A. Souhoka dkk. / Indo. J. Chem. Res., 2019, 7(1), 25-31

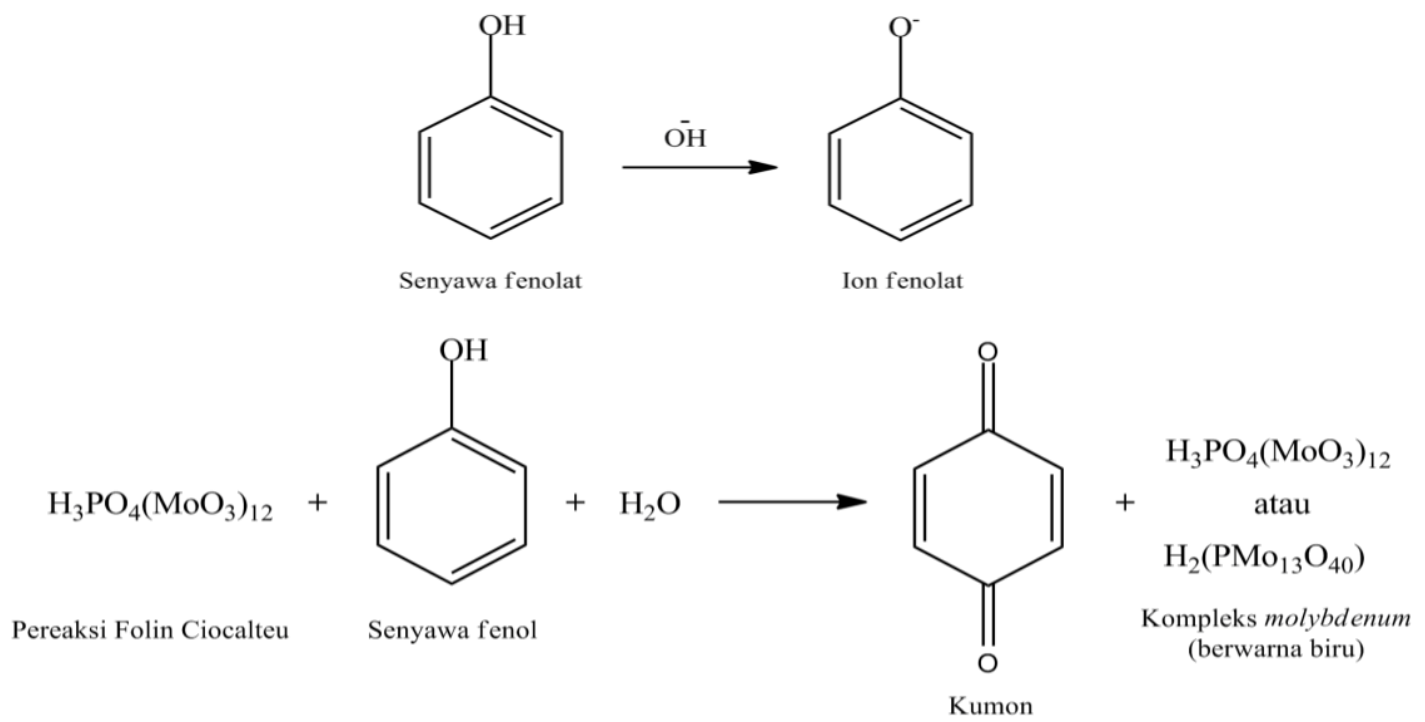

Gambar 3. Reaksi Folin-Ciocalteu dengan senyawa fenol (Conde dkk., 1997)

\section{Penentuan panjang gelombang maksimum DPPH}

Penentuan panjang gelombang maksimum DPPH dilakukan dengan mengamati serapan panjang gelombang pada rentang 490-534 $\mathrm{nm}$. Hasil yang diperoleh dibuat kurva seperti Gambar 5.

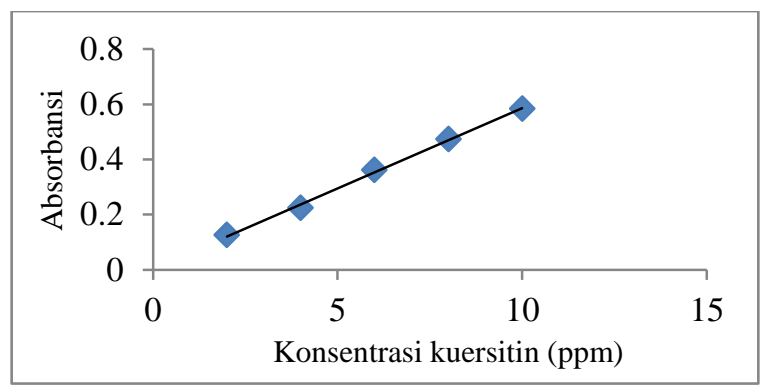

Gambar 4. Kurva standar kuersetin

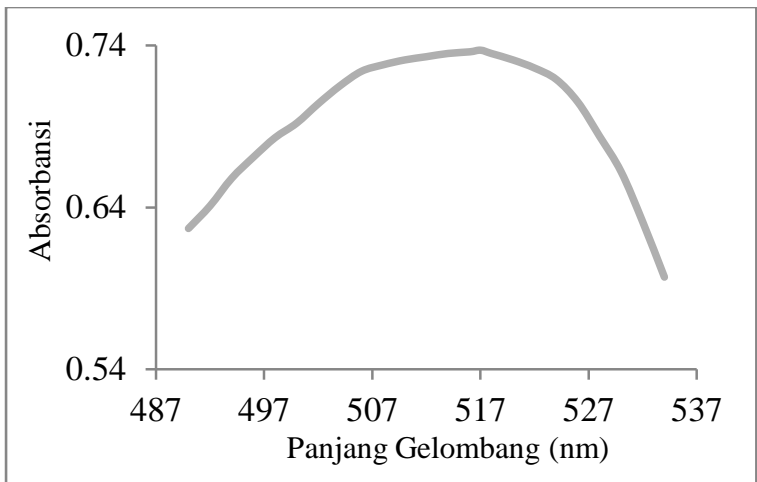

Gambar 5. Panjang gelombang maksimum DPPH
Berdasarkan Gambar 5 diperoleh panjang gelombang maksimum DPPH adalah $517 \mathrm{~nm}$. Selanjutnya panjang gelombang maksimum DPPH digunakan dalam penentuan aktivitas antioksidan.

\section{Pembuatan kurva standar}

Sebelum dilakukan penentuan aktivitas penangkal radikal bebas DPPH ekstrak metanol biji kesumba keling, dibuat kurva standar untuk menguji linearitas pada sampel. Penentuan aktivitas penangkal radikal bebas DPPH dinyatakan dengan nilai $\mathrm{IC}_{50}$ menggunakan kuersetin sebagai kontrol. Dari hasil pengukuran menggunakan UV-Vis pada panjang gelombang $517 \mathrm{~nm}$ diperoleh nilai absorbansi dari masingmasing konsentrasi. Nilai absorbansi digunakan untuk perhitungan \% Inhibisi dan $\mathrm{IC}_{50}$ kuersetin. Berdasarkan hasil perhitungan diperoleh data aktivitas penangkal radikal bebas DPPH dari kuersetin seperti disajikan pada Tabel 3.

Tabel 3. Aktivitas penangkal radikal bebas DPPH dari kuersetin

\begin{tabular}{|c|c|c|c|c|}
\hline \multirow{2}{*}{ No } & \multirow{2}{*}{$\begin{array}{c}\text { Konsentrasi } \\
\text { kuersetin } \\
(\mathrm{ppm})\end{array}$} & \multicolumn{2}{|c|}{ Abs } & \multirow{2}{*}{$\begin{array}{c}\% \\
\text { Inhibisi }\end{array}$} \\
\hline & & $\mathrm{U}_{1}$ & $\mathrm{U}_{2}$ & \\
\hline 1 & 2,5 & 0,795 & 0,781 & 21,00 \\
\hline 2 & 5,0 & 0,712 & 0,720 & 28,20 \\
\hline 3 & 7,5 & 0,450 & 0,462 & 54,26 \\
\hline 4 & 10,0 & 0,376 & 0,366 & 62,81 \\
\hline 5 & 20,0 & 0,056 & 0,051 & 94,63 \\
\hline 6 & $\begin{array}{l}\text { DPPH + } \\
\text { Metanol }\end{array}$ & 1,023 & 0,973 & - \\
\hline
\end{tabular}


Dari hasil yang diperoleh, dibuat kurva standar aktivitas penangkal radikal bebas DPPH dari kuersetin seperti ditunjukkan pada Gambar 6.

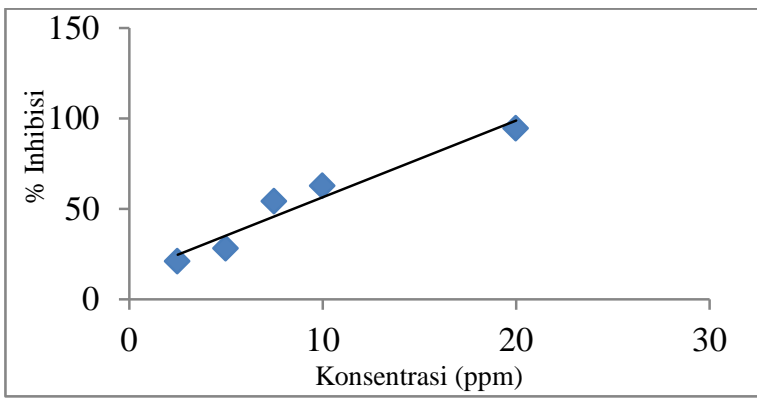

Gambar 6. Kurva standar aktivitas penangkal radikal bebas DPPH dari kuersetin

Persamaan regresi kurva standar aktivitas penangkal radikal bebas DPPH dari kuersetin digunakan untuk menentukan nilai $\mathrm{IC}_{50}$ kuersetin. Berdasarkan perhitungan diperoleh nilai IC $_{50}$ kuersetin $8,485 \mathrm{ppm}$.

\section{Penentuan aktivitas penangkal radikal bebas DPPH}

Aktivitas antioksidan ekstrak metanol biji kesumba keling diuji menggunakan metode DPPH. Uji DPPH merupakan metode yang efektif untuk menentukan aktivitas antiradikal bebas. Radikal DPPH adalah suatu senyawa organik yang mengandung nitrogen yang tidak stabil dengan absorbansi kuat pada panjang gelombang $517 \mathrm{~nm}$ dan berwarna ungu gelap. Reaksi penghambatan radikal DPPH ditunjukkan pada Gambar 7.<smiles>CC(C)[Mg]</smiles>

DPPH•<smiles>O=[N+]([O-])c1cc([N+](=O)[O-])c(NN(c2ccccc2)c2ccccc2)c([N+](=O)[O-])c1</smiles>

DPPH-H
Gambar 7. Reaksi penghambatan radikal DPPH (Prakash, 2001)

Penentuan aktivitas penangkal radikal bebas DPPH dilakukan dengan mengamati serapan pada panjang gelombang $517 \mathrm{~nm}$. Absorbansi ekstrak metanol biji kesumba keling disajikan pada Tabel 4.

Tabel 4. Hasil pengukuran absorbansi ekstrak metanol biji kesumba keling

\begin{tabular}{ccc}
\hline No & $\begin{array}{c}\text { Ekstrak metanol biji } \\
\text { kesumba keling }\end{array}$ & Absorbansi \\
\hline 1 & P1 & 0,390 \\
2 & P2 & 0,402 \\
\hline
\end{tabular}

Dari hasil pengukuran, dibuat kurva aktivitas penangkal radikal bebas DPPH ekstrak metanol biji kesumba keling seperti ditunjukkan pada Gambar 8. Ekstrak metanol biji kesumba keling menunjukkan peningkatan \% inhibisi tiap konsentrasinya. Persen inhibisi diperoleh dari perbedaan absorbansi kontrol dengan absorbansi sampel. Selanjutnya, penentuan aktivitas penangkal radikal bebas DPPH digunakan parameter $\mathrm{IC}_{50}$. Penentuan $\mathrm{IC}_{50}$ dari sampel yang diekstrak bertujuan untuk menentukan jumlah kandungan ekstrak yang dapat menurunkan intensitas serapan radikal bebas DPPH sebesar $50 \%$ dibandingkan dengan larutan kontrol. Semakin kecil nilai $\mathrm{IC}_{50}$, semakin tinggi aktivitas antioksidan. Ekstrak metanol biji kesumba keling mengandung senyawa flavonoid yang dapat menyumbangkan elektron untuk menangkal radikal bebas.

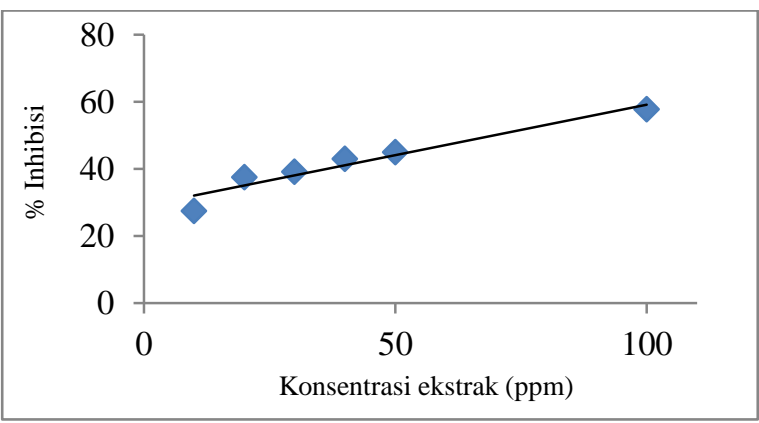

Gambar 8. Penentuan aktivitas penangkal radikal bebas DPPH ekstrak metanol biji kesumba keling

Berdasarkan hasil perhitungan, diperoleh aktivitas penangkal radikal bebas DPPH ekstrak metanol biji kesumba keling dengan persamaan regresi $y=0,3012 x+29,089$ dan nilai $\mathrm{IC}_{50}$ adalah 69,425 ppm. Nilai ini menunjukkan ekstrak metanol biji kesumba keling tergolong antioksidan kuat $\left(50<\mathrm{IC}_{50}<100 \quad \mathrm{ppm}\right)$. Dibandingkan dengan penelitian sebelumnya, Suhaling (2016), menentukan aktivitas antioksidan ekstrak metanol kacang merah 
(Phaseolus vulgaris L) dengan Metode DPPH, diperoleh nilai $\mathrm{IC}_{50} 164,44 \mathrm{ppm}$, sehingga tergolong antioksidan lemah. Widianingsih (2016), menguji aktivitas antioksidan ekstrak metanol buah naga merah (Hylocereus polyrhizy) hasil maserasi dan dipekatkan dengan kering angin diperoleh nilai $\mathrm{IC}_{50} 67,42 \mathrm{ppm}$, sehingga tergolong antioksidan kuat.

\section{KESIMPULAN}

Berdasarkan hasil penelitian, maka dapat disimpulkan bahwa ekstrak metanol biji kesumba keling mengandung senyawa flavonoid dan memiliki aktivitas antioksidan yang ditunjukkan dengan nilai $\mathrm{IC}_{50}$ sebesar $69,425 \mathrm{ppm}$, sehingga tergolong sebagai antioksidan kuat.

\section{DAFTAR PUSTAKA}

Alhabsyi, D. F., Suryanto, E., dan Wewengkang, D. S., 2014, Aktivitas Antioksidan dan Tabir Surya pada Ekstrak Kulit Buah Pisang Goroh (Musa acuminate L), Pharmacon J. Ilmiah Farmasi, 3(2), 107-114.

Burda, S., dan Oleszek, W., 2001, Antioxidant and Antiradical Activities of Flavonoids, $J$. Agric. and Food Chem., 49(6), 2774-2779.

Conde, E., Cadahia, M. C., Vallejo, G., Simon, B. E. D., dan Adrados, J. R. G., 1997, Low Molecular Weight Polyphenol in Cork of Quercus suber, J. Agric. and Food Chem., 45(7), 2695-2700.

Gardjito M., 2013, Bumbu, Penyedap, dan Penyerta Masakan Indonesia, PT. Gramedia Pustaka Utama, Jakarta.

Harbone J. B., 2006, Metode Fitokimia: Penuntun Cara Modern Menganalisis Tumbuhan, Terjemahan dari: Phytochemical Method, Penerjemah; Padmawinata K., Soediro I., ITB, Bandung.

Mahardika, R., Roanisca, O., 2018, Aktivitas Antioksidan dan Fitokimia dari Ekstrak Etil Asetat Pucuk Idat (Cratoxylum glaucum). Indo. J. Chem. Res., 5(2), 6974.

Molyneux, P., 2004, The Use of The Stable Free Radical Diphenylpicrylhydrazil (DPPH) for Estimating Antioxidant Activity, J. Sci. Technol., 26(2), 211-219.

Mira E., Anggraini D., Sukmayani P., 2013, Formulasi Sediaan Pewarna Bibir dari Ekstrak Etanol Biji Buah Kesumba Keling
(Bixa orellana L), Jurnal Scientia, 3(1), 2934.

Mulyani, W., Idiawati, N., dan Gusrizal, 2013, Aktivitas Antioksidan Ekstrak n-Heksana, Etil Asetat, dan Metanol Kulit Buah Jeruk Sambal (Citrus microcarpa Bunge), Jurnal Kimia Khatulistiwa, 2(2), 90-94.

Nafisah, M., Tukiran, Suyanto, Hidayati, N., 2017, Skrining Fitokimia dan Analisis Kromatografi Lapis Ekstrak Tanaman Patikan Kebo (Euphorbiae hirta L), Medicamento, 3(2), 61-70.

Prakash, A., 2001, Antioxidant Activity, Medallion Laboratories: Analytical Progress, 19(2), 1-4.

Pujilestari T., 2014, Pengaruh Ekstraksi Zat Warna Alam dan Fiksasi terhadap Ketahanan Luntur Warna pada Kain Batik Katun, Dinamika Kerajinan dan Batik, 31(1), 31-40.

Purwaningsih, D., 2013, Pemanfaatan Biji Tanaman Kesumba (Bixa orellana L) sebagai Pewarna Alami dan Antioksidan (Vitamin C) untuk Pembuatan Kue Bolu dari Berbagai Macam Tepung, Skripsi, Fakultas Keguruan dan Ilmu Pendidikan, Universitas Muhammadiyah Surakarta, Solo.

Rustiah, W., Umriani, N., 2018, Uji Aktivitas Antioksidan Pada Ekstrak Buah Kawista (Limonia Acidissima) Menggunakan Spektrofotometer UV-Vis., Indo. J. Chem. Res., 6(1), 22-25.

Sadikin, M., 2008, Radikal Bebas Harus Dikendalikan, Media Indonesia, 27 Februari 2008, hal. 17.

Suhaling, S., 2010, Uji Aktivitas Antioksidan Ekstrak Metanol Kacang Merah (Phaseolus vulgaris L) dengan Metode DPPH, Skripsi, Fakultas Kedokteran dan Ilmu Kesehatan, Universitas Islam Negeri Alauddin, Makassar.

Tiwari, P., Kumar, B., Kaur, M., Kaur, H., 2011, Phytochemical Screening and Extraction: A Review, Internationale Pharmaceutica Scienciea, 1(1), 96-106.

Widianingsih, M., 2016, Aktivitas Antioksidan Ekstrak Metanol Buah Naga Merah (Hylocereus polyrhizy (F.A.C. Weber) Britton \& Rose) Hasil Maserasi dan dipekatkan dengan Kering Angin, Jurnal Wiyati, 3,(2), 146-150. 